Modeling the effect of direct and indirect contamination of on-farm bulk tank milk with Mycobacterium avium subsp. paratuberculosis

Okura, Hisako; Nielsen, Søren Saxmose; Toft, Nils

Published in:

Foodborne pathogens and disease

DOI:

10.1089/fpd.2012.1280

Publication date:

2013

Document version

Publisher's PDF, also known as Version of record

Citation for published version (APA):

Okura, H., Nielsen, S. S., \& Toft, N. (2013). Modeling the effect of direct and indirect contamination of on-farm

bulk tank milk with Mycobacterium avium subsp. paratuberculosis. Foodborne pathogens and disease, 10(3), 270-277. https://doi.org/10.1089/fpd.2012.1280 


\title{
Modeling the Effect of Direct and Indirect Contamination of On-Farm Bulk Tank Milk with Mycobacterium avium subsp. paratuberculosis
}

\author{
Hisako Okura, Søren S. Nielsen, and Nils Toft
}

\begin{abstract}
Mycobacterium avium subsp. paratuberculosis (MAP) in milk of bovine origin is suspected of being implicated in Crohn's disease in humans. Milk can be contaminated via direct excretion of MAP in milk or indirectly via fecal contamination of the milk. This study aimed at estimating the level of MAP in farm bulk tank milk and simulating the effect of direct and indirect contamination with MAP. The effect of discarding milk from testpositive cows at different prevalences was assessed. The concentration of MAP in milk was estimated using a simulation model, while taking direct and indirect contamination with MAP into account. Direct MAP contamination of milk was related to infection stages, while indirect contamination was associated with within-herd prevalence and distribution of cows in different stages of infection. Discarding of milk based on diagnostic test results was included as a control option. Median MAP load in farm bulk tank milk at within-herd infection prevalences from $7.5 \%$ to $60 \%$ were estimated to be $0.54-7.53 \mathrm{CFU} / \mathrm{mL}$ milk. Maximum concentration at the prevalence of $60 \%$ could be $1186 \mathrm{CFU} / \mathrm{mL}$ caused by shedding of high amounts of MAP in feces. At the prevalence of $15 \%$, discarding milk from test positive cows would result in discarding $11 \%$ of milk and reduce the MAP level by $80 \%$. Due to poor sensitivity of the diagnostic test, removing test-positive cows would not further reduce the already low concentration of MAP and it would not guarantee the milk as MAP-free. The model was relatively simple yet capable of capturing true infection status and associated contributions from milk and feces. Further knowledge on distribution of fecal excretion from infected cows is required because very few "super-shedders" might play a major role.
\end{abstract}

\section{Introduction}

$\mathbf{M}$ YCOBACTERIUM AVIUM subsp. paratuberculosis (MAP), the causative agent of paratuberculosis, has been speculated as a cause of Crohn's disease in humans (Behr and Kapur, 2008; Chiodini et al., 2012). Milk contaminated with MAP has been considered to be a potential source of exposure to humans (Grant, 2005). Most milk produced on cattle farms in dairy-producing countries is pasteurized, which may reduce MAP in milk by $4-7 \log _{10}$ (Cerf et al., 2007). However, MAP bacteria and DNA have been found in dairy products in retail stores, indicating survival of MAP during the processing (Ellingson et al., 2005; Stephan et al., 2007). The increasing implications of the role of MAP in Crohn's disease suggest that minimizing contamination of milk at the farm level may be advisable.

MAP infection in cows follows different infection stages as described in detail elsewhere (Coussens et al., 2004). Briefly, in the early stage of infection, the host response is predomi- nantly a cell-mediated immune response (CMI), where the infection remains latent but MAP proliferates in the jejunum and ileum and spreads to local lymph nodes. The cow may shed MAP in feces at low levels, often below the detection limit, and possibly also in milk if disseminated infection has occurred (Sweeney et al., 2006; Stabel et al., 2009). The latter is still uncertain. Then the infection may progress to a more advanced stage, where the cow sheds higher numbers of MAP into the milk and feces. This stage is characterized by a humoral immune (HI) response and occurrence of IgG1, and these cows are more likely to be detected by a diagnostic test such as enzyme-linked immunosorbent assay (Nielsen and Ersbøll, 2006).

Milk from an infected cow can be contaminated directly via MAP shedding in milk and indirectly from fecal contamination of the milk from that cow. MAP contamination in bulk tank milk is affected by other factors such as within-herd infection prevalence, herd size, and hygienic measures at milking, because the contamination can occur from infectious

Department of Large Animal Sciences, University of Copenhagen, Frederiksberg, Denmark. 
cows and indirectly by cross-contamination from feces of other MAP-infected cows (Clough et al., 2006). Although we theoretically know the role of infected cows, minimizing MAP contamination of bulk tank milk is not a simple task, because existing diagnostic tests are imperfect and the relationship between the infection stages and shedding is not well understood. Therefore, it is unclear whether removing testpositive cows from milking would effectively reduce MAP contamination of bulk tank milk.

Simulation modeling is useful to capture the combination of these phenomena, which can be impossible to observe in field studies. Previous models for MAP in bulk tank milk have mainly focused on clinically affected animals with obvious high concentrations of MAP in feces and rarely discuss the role of cows in earlier stages of infection (Nauta and van der Giessen, 1998; Weber et al., 2008; Boulais et al., 2011). Taking one step further, a model should also be able to assess the effect of differences in infection prevalence and herd sizes on the level of contamination.

The objective of this study was to estimate the level of MAP in on-farm bulk tank milk and assess the effect of direct and indirect MAP contamination of bulk tank milk using a simulation model. Furthermore, the impact of discarding milk of test-positive cows on MAP levels in bulk tank milk was assessed.

\section{Materials and Methods}

We created a simulation model to estimate possible MAP load in on-farm bulk tank milk on a given day. A herd consisted of cows in different infection stages: noninfected, early stage of infection where the host response is a predominant cell-mediated immune response (infected with $\mathrm{CMI}$ ), and a later stage of infection characterized by a humoral immune response and occurrence of IgG1 (infected with HI). Milk production, MAP excretion in the milk, and MAP shedding in the feces of these cows contributed to the per-day milk production and the MAP concentration in the bulk tank milk. Basically, bulk tank milk contamination with MAP was the sum of direct excretion to the milk and indirect contamination via feces from infected cows. Input parameters were parameterized using existing data. The outline of the model is illustrated in Figure 1 with model input as specified below and in Table 1. The model was implemented in R (R Development Core Team, 2010). The $R$ code is available upon request.

\section{Input parameters}

Milk yield. Milk yield was included to capture the dilution factor from each cow and was estimated by fitting the Wilmink function (Wilmink, 1987), a model widely used for milk yield, on milk production data from 57,134 Holstein cows from 279 herds obtained from the Danish Cattle Database. The cows in the dataset were stratified by parity group $(1,2$, and $>2$ ), and the model accounted for random effects of the individual animals and the herd of origin. These cows were considered to be a representative sample of the Danish dairy cattle population.

Distribution of MAP concentration in milk from cow infected with $\mathrm{CMI}$ and $\mathrm{HI}$. Quantitative information on MAP in milk from infected cows is limited. Gao et al. (2009) observed the frequency of the number of CFU isolated per milk sample from individual cows previously tested positive by either fecal culture or antibody enzyme-linked immunosorbent assay based on 46 positive samples out of 133 assayed. The concentration of MAP in 40 out of the 46 samples was between 1 and 1.4 CFU $/ 15 \mathrm{~mL}$ of milk samples, whereas the remaining six samples had more than $24 \mathrm{CFU} / \mathrm{mL}$. Based on these data, MAP in individual milk from infected cows was estimated using a negative binomial distribution $(\theta=0.756, \mu=12)$, corresponding to a mean of $12 \mathrm{CFU} / \mathrm{mL}$. Cows with CMI were assumed to excrete $10 \%$ of the MAP shed by HI cows.

Distribution of MAP concentration in feces from cows infected with $\mathrm{CMI}$ and $\mathrm{HI}$. The distribution of MAP CFU in feces was based on data from 786 dairy cows in 93 U.S. dairy herds (Crossley et al., 2005). The observed number of CFU per tube ranged from $0.25 \mathrm{CFU} /$ tube to numbers too numerous to count. Based on these data, a Weibull distribution (shape $=$ 0.17 , scale $=0.006$ ) was estimated, corresponding to a mean of $3.5 \times 10^{6} \mathrm{CFU} / \mathrm{g}$ feces while the maximum concentration was set to $10^{9} \mathrm{CFU} / \mathrm{g}$ feces. Cows with CMI were assumed to excrete $10 \%$ of the MAP shed by HI cows.

Distribution of amount of feces contaminating bulk tank milk. A study on Escherichia coli contamination to bulk tank milk considered that fecal contamination of the bulk tank is likely to range from close to $0 \mathrm{~g}$ feces in the milk from all milking cows in a herd on most clean farms to $10 \mathrm{~g}$ on dirty farms (Clough et al., 2006). Therefore, a gamma distribution
FIG. 1. Model structure for estimation of $M y$ cobacterium avium subsp. paratuberculosis (MAP) in on-farm bulk tank milk, showing the flow between status of an individual cow and bulk tank milk collected from the herd. First, information on each cow in a herd was assigned. Then, together with that information and herd infection prevalence, the true infection status for each cow was assigned followed by the test response based on the age and parity of the cow. Milk yield, fecal contamination, MAP shedding in milk, and MAP shedding in feces were determined for each cow. Information on bulk tank milk was based on collection of information on each cow in the herd. CMI, cell-mediated immune response; HI, humoral immune response.

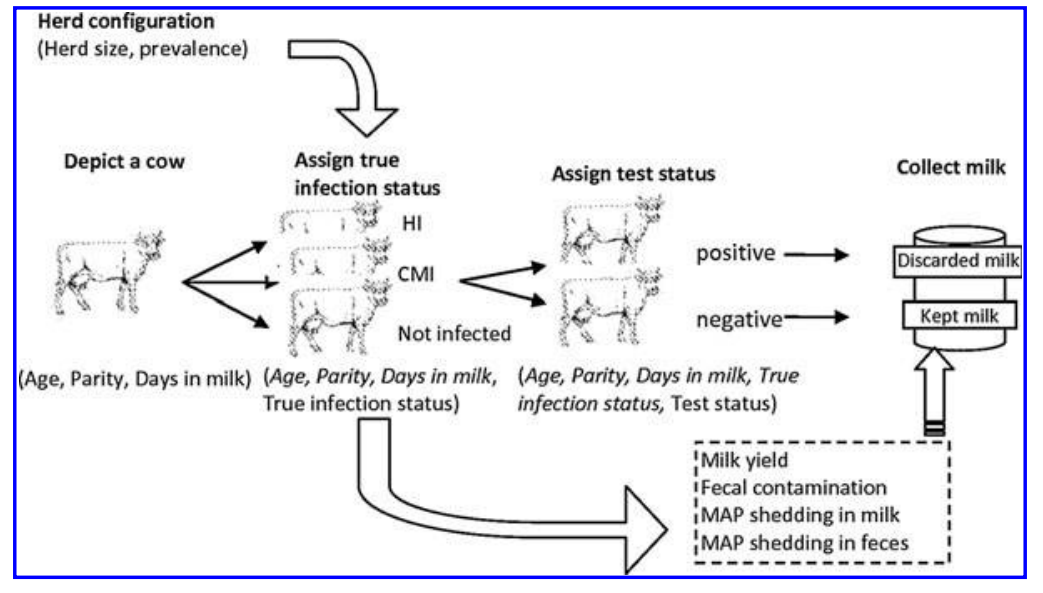




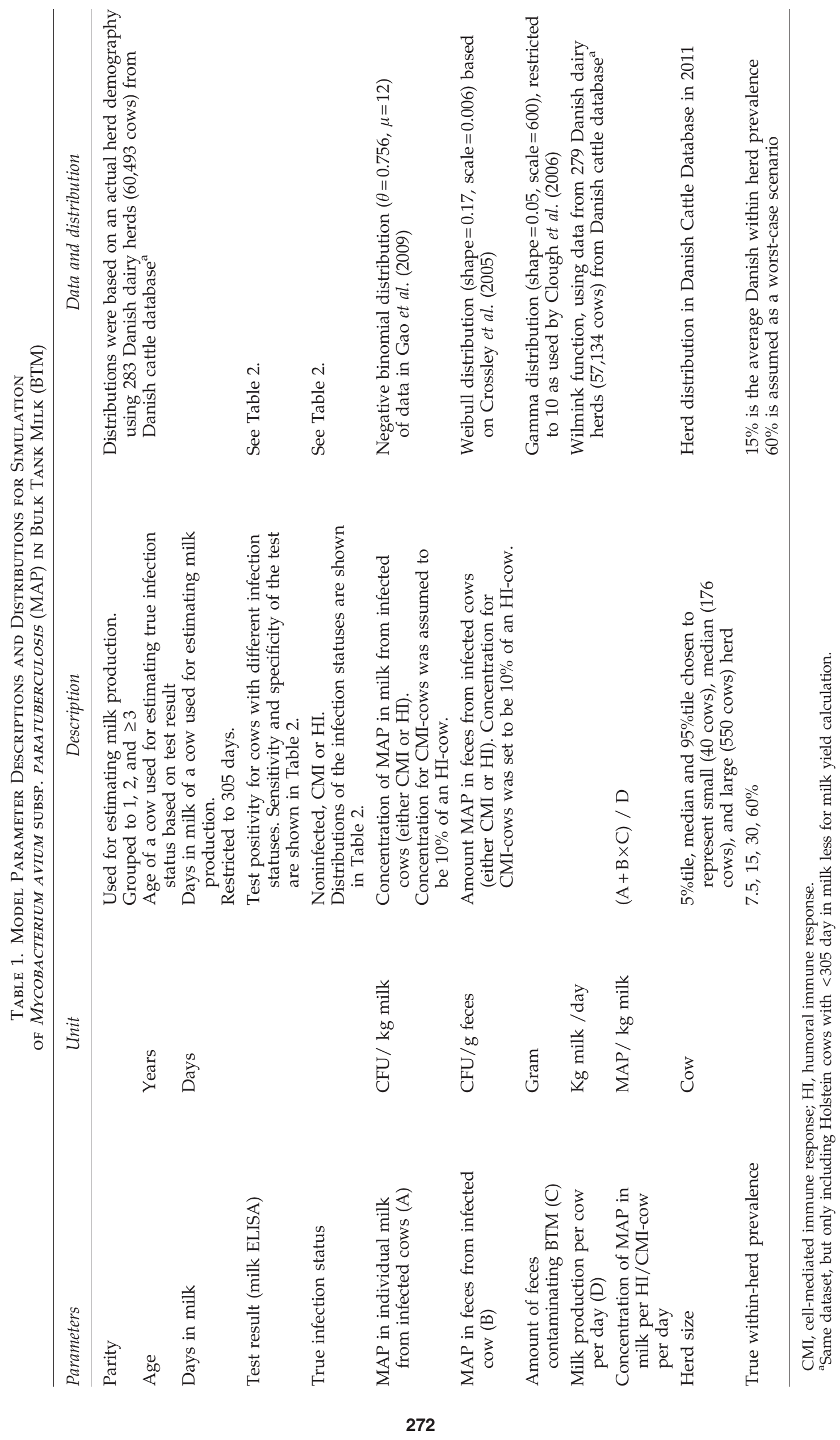


(shape $=0.05$, scale $=600$ ) was chosen to represent total amount of feces contaminating the bulk tank milk, corresponding to a mean of $0.03 \mathrm{~g}$ per animal. The distribution was set to have the maximum of $10 \mathrm{~g}$ because the tail of the gamma distribution could become unrealistically large.

Herd demography. Information on herd demography such as age, parity, and days in milk was obtained from 60,493 cows from 283 herds recorded in the Danish Cattle Database. The information was used to provide the information on each cow when a herd was configured during the simulation. Furthermore, in order to assess the effect of herd size on dilution of MAP in bulk tank milk, a small (40 cows), a medium (176 cows), and a large (550 cows) herd was chosen to represent approximately the median, $5^{\text {th }}$, and $95^{\text {th }}$ percentiles of the herd sizes in Danish dairy herds in 2011.

True within-herd MAP infection prevalence. The simulation was run for four $(7.5 \%, 15 \%, 30 \%$, and $60 \%)$ different true infection prevalences.

\section{Herd configuration}

The herd configuration in the simulation is described in Fig. 1. Each cow in a herd was assigned age, parity, and days in milk. Based on the true infection prevalence, each cow was assigned a true infection status (noninfected, or infected with CMI or HI). The test status of the cow was simulated based on the cow information and the true infection status as well as the sensitivity and specificity in Table 2 . The model calculated 1000 iterations of milkings for the herd and performed 100 simulations for each herd setting.

\section{Discarding milk}

Discarding milk from test positive cows was included as a control option to assess the effect of exclusion of MAP-infected cows' milk from the food supply. On the farm, this could be carried out by collecting milk separately based on diagnostic test results and excluding milk of test-positive cows from the bulk tank. Therefore, in the model, only milk from test-negative cows was collected to the bulk tank and thus only direct shedding in milk and indirect contamination of feces from testnegative cows contributed the MAP contamination in the bulk tank milk. Milk from test-positive cows was recorded as discarded and kept separately in order to assess the contribution from test positive versus test-negative cows.

\section{Output}

Model outputs included the number of cows in the different infection stages, the number of cows testing positive, the concentration of MAP in bulk tank milk when collected only from test negative cows, the concentration of MAP in bulk tank milk regardless of the test results, the amount of feces contaminating the bulk tank milk, the concentration of MAP in milk and feces, and the amount of milk yield in total. Results from each of the 100 simulations were stored in separate files and used for descriptive analysis. These results were summarized using the median values and the 95th percentiles representing an "average" upper value. The maximum of the maximum values was used to represent the worst-case scenario. The number of iterations affects the maximum of the

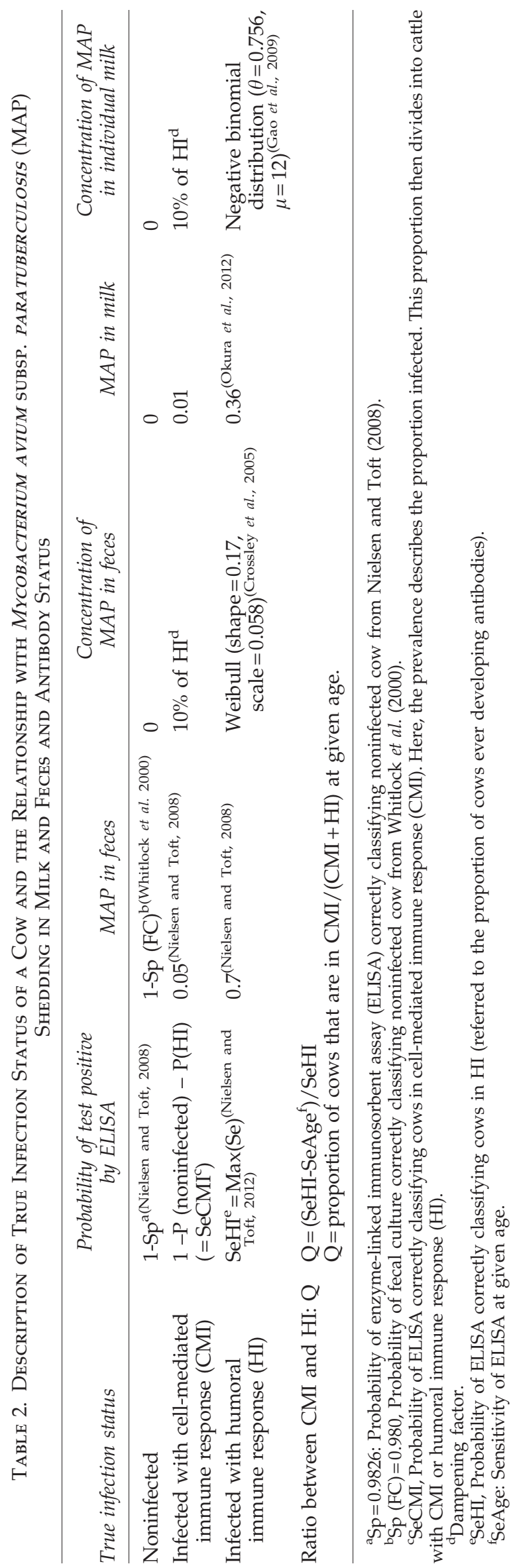




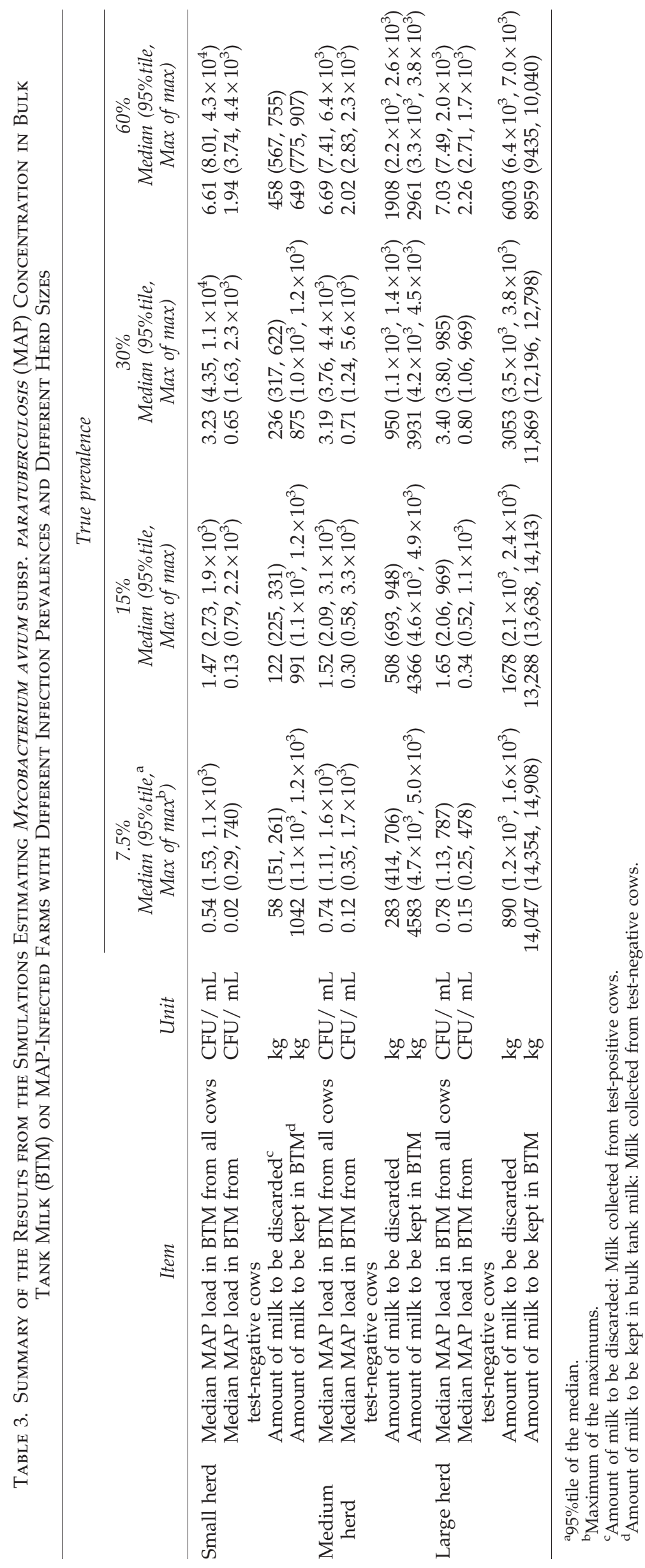


maximum, and 1000 iterations would cover approximately 3 years for a specific herd.

\section{Sensitivity analysis}

The relative MAP excretions from CMI cows, as well as the amount of MAP in milk and feces, were considered to include the primary uncertainty in the model, caused by uncertainty in the published literature. Therefore, these parameters were subject to sensitivity analysis, where the described default MAP concentrations in milk and feces were increased 10 and 100, and 10 and 1000 times, and the relative MAP excretion from CMI cows was reduced to $1 \%$.

\section{Results}

Median concentrations of MAP in bulk tank milk collected from all cows (i.e., regardless of the test result) grouped by the herd size and true within-herd prevalence and the amount of milk to be discarded in each scenario are summarized in Table 3.

The median concentrations of MAP in bulk tank milk were generally low. However, the maximum of maximum concentrations were higher for the small herds, when mixing the milk from all cows. The concentration of bulk tank milk for a small herd with true within-herd prevalence of $60 \%$ could reach $4.3 \times 10^{5} \mathrm{CFU} / \mathrm{mL}$ in the worst-case scenario. When comparing the concentration among the herd sizes at the same true within-herd prevalence, the concentrations were almost constant across the herd sizes.

Discarding milk from test-positive cows resulted in discarding relatively large amounts of milk without reducing the concentration of MAP significantly. For example, for the medium-sized herd at $15 \%$ true prevalence, discarding milk would result in discarding approximately $10 \%$ of the milk, while the reduction in the concentration was only $84 \%$ or less than $1 \log _{10}$.
Table 4 shows the amount of feces of test-positive and testnegative cows that contaminated the bulk tank milk; the MAP concentrations are also shown. The amount of feces of testpositive cows contaminating the bulk tank milk was 2-30\% smaller than that of test-negative cows, while the concentration of the feces could be 3-10 times larger than that of testnegative cows.

Herd size, or the dilution effect, was not an important factor to the concentration, because the median concentrations were always very low. However, in the worst-case scenario with a cow shedding extreme amounts of MAP ( $>10^{9} \mathrm{CFU} / \mathrm{g}$ feces) in feces in a small herd, the milk would not be diluted and the bulk tank could contain $4.3 \times 10^{4} \mathrm{CFU} / \mathrm{mL}$ (Tables 3 and 4).

The sensitivity analysis showed that (1) reducing excretion of MAP from $10 \%$ to $1 \%$ of excretion from $\mathrm{HI}$ and (2) increasing the MAP excretion in milk did not change the MAP concentration in the bulk tank milk. However, increasing the MAP excretion in feces increased the MAP level in the bulk tank milk on the order of $10^{3}$ (Table 5).

\section{Discussion}

The median estimated MAP load in the bulk tank milk on a farm ranged from 0.54 to $7.03 \mathrm{CFU} / \mathrm{mL}$, depending on the prevalence and the herd size. These MAP loads were generally low, but in worst-case scenarios, the concentration could be $10^{4} \mathrm{CFU} / \mathrm{mL}$ due to high MAP concentrations in feces.

The low median concentration of MAP in bulk tank milk was similar to other models (Weber et al., 2008; Boulais et al., 2011). However, the stochastic model enabled infrequent but plausible case scenarios, such as a herd containing a few cows shedding extreme amounts of MAP in feces. The resulting high amount of MAP in such a worst-case scenario is considered not to occur on a daily basis, but it is still plausible. Raw, nonpasteurized milk may thus contain up to $10^{4} \mathrm{CFU} /$ $\mathrm{mL}$. If pasteurization could be expected to reduce MAP in milk by 4 to 5 logs, the median concentrations found in our

Table 4. Summary of the Results from the Simulations Estimating Fecal Contamination to Bulk Tank Milk on Medium-Sized Herd (175 Cows) ANd the Concentration of MYCOBACTERIUM AVIUM SUbSP. PARATUBERCULOSIS (MAP)

\begin{tabular}{|c|c|c|c|c|c|}
\hline $\begin{array}{l}\text { True within-herd } \\
\text { prevalence }\end{array}$ & $\begin{array}{l}\text { Test } \\
\text { result }\end{array}$ & $\begin{array}{c}\text { Median number } \\
\text { of cows positivel } \\
\text { negative }^{\mathrm{b}}\end{array}$ & $\begin{array}{l}\text { Median number } \\
\text { of cows HI/CMI/ } \\
\text { not infected }\end{array}$ & $\begin{array}{l}\text { Median amount of } \\
\text { feces contaminating } \\
\text { the bulk tank (gram) }\end{array}$ & $\begin{array}{c}\text { Median concentration } \\
\text { of MAP in the feces } \\
\text { (CFU/gram feces) }\end{array}$ \\
\hline 7.5 & $\begin{array}{l}\text { Positive } \\
\text { Negative }\end{array}$ & $\begin{array}{r}10 \\
165\end{array}$ & $\begin{array}{r}9 \\
4 \\
162\end{array}$ & $\begin{array}{l}0.13 \\
4.74\end{array}$ & $\begin{array}{l}5 \times 10^{2} \\
6 \times 10^{1}\end{array}$ \\
\hline 15 & $\begin{array}{l}\text { Positive } \\
\text { Negative }\end{array}$ & $\begin{array}{r}17 \\
158\end{array}$ & $\begin{array}{r}18 \\
7 \\
149\end{array}$ & $\begin{array}{l}0.33 \\
4.50\end{array}$ & $\begin{array}{l}7 \times 10^{3} \\
2 \times 10^{3}\end{array}$ \\
\hline 30 & $\begin{array}{l}\text { Positive } \\
\text { Negative }\end{array}$ & $\begin{array}{r}33 \\
142\end{array}$ & $\begin{array}{r}38 \\
15 \\
122\end{array}$ & $\begin{array}{l}0.80 \\
4.04\end{array}$ & $\begin{array}{l}6 \times 10^{4} \\
2 \times 10^{4}\end{array}$ \\
\hline 60 & $\begin{array}{l}\text { Positive } \\
\text { Negative }\end{array}$ & $\begin{array}{r}67 \\
108\end{array}$ & $\begin{array}{l}79 \\
28 \\
69\end{array}$ & $\begin{array}{l}1.81 \\
3.06\end{array}$ & $\begin{array}{l}4 \times 10^{5} \\
1 \times 10^{5}\end{array}$ \\
\hline
\end{tabular}

${ }^{\text {a }}$ Under the control option, feces from test-positive cows would be discarded and not contribute to the MAP load in the bulk tank.

${ }^{\mathrm{b}}$ Number of cows tested positive/negative to the diagnostic test.

${ }^{c}$ Number of cows with true infection status. 


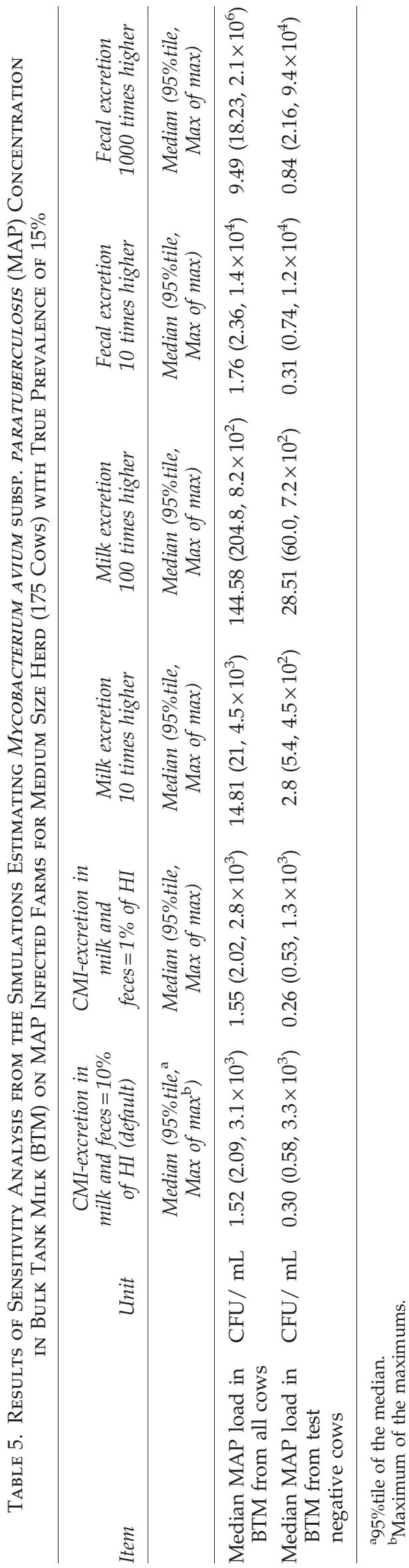

simulations are sufficiently low to ensure that all MAP in milk is reduced to very low levels. Previous studies on the effectiveness of heat inactivation of MAP suggest that up to a $7 \mathrm{log}$ reduction of MAP can be obtained after heat inactivation (Rademaker et al., 2007). Our estimated MAP concentration in raw milk was $10^{4} \mathrm{CFU} / \mathrm{mL}$ in the worst case; therefore heat inactivation should be effective. Still, MAP isolation in milk sampled at retail stores has been reported (Ellingson et al., 2005; Stephan et al., 2007). It has recently been reported that spore-forming MAP may survive heat treatments of $70^{\circ} \mathrm{C}$ (Lamont et al., 2012), which could explain the occasional MAP survival after heat treatments. Other possible explanations for the difference between our predictions and the apparent pasteurization inefficiency include the following: (1) inappropriate pasteurization was conducted for the retail store samples; (2) the maximum amount of feces per cow is much higher than the $10 \mathrm{~g} / \mathrm{cow}$ we used; or (3) the maximum amount of MAP per gram of feces is much higher than that included in our model. However, it is not possible to validate those features (see below).

In the model, discarding milk from test-positive cows was included because removal of products of MAP-infectious cows from the food chain might be proposed. This could be managed using available diagnostic tests, but the tests lack sensitivity and fail to detect all infectious cows (Table 4). Thus, this strategy might be insufficient if pasteurization does not kill MAP at concentrations of $10^{4}$, because fecal contamination from test-negative cows seems to provide an infectious load sufficient to result in significant amounts of MAP in milk under very poor hygienic circumstances. Therefore, removing test-positive cows would not guarantee the milk as being MAP free.

A sensitivity analysis was performed to address a reduction in the recovery of MAP from milk and fecal samples (Whittington, 2010). This analysis suggested that the level of MAP in feces primarily affects the results, whereas other parameters have little effect.

Limitations of the model include the assumptions we made relating to the infection status of a cow with the probability and concentration of shedding of MAP in milk and feces. The model only included two infection stages, but essentially allowed cows progressing in infection with age and mimicked the expected distribution between infection stages. Begg et al. (2011) reported that sheep could distribute in three populations: (1) CMI alone; (2) both CMI and HI; or (3) HI alone. If this is the case for cattle as well, the results would be affected. However, there are no data to distinguish between these two groups and thus form the basis for differences in MAP excretion patterns. Therefore, a parsimonious model seemed more appropriate. Furthermore, we assumed that MAP shedding in milk and feces from cows with CMI is $10 \%$ of that from cows with $\mathrm{HI}$, because there are no studies associating specific infection stages with shedding MAP in both milk and feces. Cows with CMI are considered subclinical, and these cows include those intermittently shedding low levels of MAP in milk and feces. Therefore, our assumption of $10 \%$ could overestimate the level and variability of the concentration, but the sensitivity estimates showed that the results were not really affected. Furthermore, the model assumed that the fecal contamination of the bulk tank is the same regardless of the herd characteristics and extrapolated the data from the Escherichia coli study (Clough et al., 2006). We truncated the fecal contamination modeled using a gamma distribution with a 
long right tail at $10 \mathrm{~g}$. Nonetheless, the role of indirect contamination highlights the importance of hygiene on farms by avoiding fecal contamination of the bulk tank milk.

\section{Conclusion}

The simulated MAP concentration in bulk tank milk is low, particularly when considering only the MAP shed directly in the milk. Hygiene on farms is important because MAP concentrations could reach $10^{4} \mathrm{CFU} / \mathrm{mL}$ in the presence of cows shedding extreme (but plausible) amounts of MAP in the feces. Fecal contamination was seen as the primary source of MAP contamination in the bulk tank milk.

\section{Acknowledgments}

We would like to thank B. Crossley and I. Gardner for providing the data on fecal shedding.

\section{Disclosure Statement}

No competing financial interests exist.

\section{References}

Begg DJ, de Silva K, Carter N, Plain KM, Purdie A, Whittington RJ. Does a Th1 over Th2 dominancy really exist in the early stages of Mycobacterium avium subspecies paratuberculosis infections? Immunobiology 2011;216:840-846.

Behr MA, Kapur V. The evidence for Mycobacterium paratuberculosis in Crohn's disease. Curr Opin Gastroenterol 2008; 24:17-21.

Boulais C, Wacker R, Augustin JC, Cheikh MH, Peladan F. Modeling the occurrence of Mycobacterium avium subsp. paratuberculosis in bulk raw milk and the impact of management options for exposure mitigation. J Food Prot 2011;74:1126-1136.

Cerf O, Griffiths M, Aziza F. Assessment of the prevalence of Mycobacterium avium subsp. paratuberculosis in commercially pasteurized milk. Foodborne Pathog Dis 2007;4:433-447.

Chiodini RJ, Chamberlin WM, Sarosiek J, McCallum RW. Crohn's disease and the mycobacterioses: A quarter century later. Causation or simple association? Crit Rev Microbiol 2012;38:52-93.

Clough HE, Clancy D, French NP. Vero-cytotoxigenic Escherichia coli $\mathrm{O} 157$ in pasteurized milk containers at the point of retail: A qualitative approach to exposure assessment. Risk Anal 2006;26:1291-1309.

Coussens PM. Model for immune responses to Mycobacterium avium subspecies paratuberculosis in cattle. Infect Immun 2004; 72:3089-3096.

Crossley BM, Zagmutt-Vergara FJ, Fyock TL, Whitlock RH, Gardner IA. Fecal shedding of Mycobacterium avium subsp. paratuberculosis by dairy cows. Vet Microbiol 2005;107:257-263.

Ellingson JL, Anderson JL, Koziczkowski JJ, Radcliff RP, Sloan SJ, Allen SE, Sullivan NM. Detection of viable Mycobacterium avium subsp. paratuberculosis in retail pasteurized whole milk by two culture methods and PCR. J Food Prot 2005;68:966-972.

Gao A, Odumeru J, Raymond M, Hendrick S, Duffield T, Mutharia L. Comparison of milk culture, direct and nested polymerase chain reaction (PCR) with fecal culture based on samples from dairy herds infected with Mycobacterium avium subsp. paratuberculosis. Can J Vet Res 2009;73:58-64.
Grant IR. Zoonotic potential of Mycobacterium avium ssp. paratuberculosis: The current position. I Appl Microbiol 2005;98: 1282-1293.

Lamont EA, Bannantine JP, Armien A, Ariyakumar DS, Sreevatsan $S$. Identification and characterization of a spore-like morphotype in chronically starved Mycobacterium avium subsp. paratuberculosis cultures. PLoS ONE 2012;7:e30648.

Nauta MJ, van der Giessen JW. Human exposure to Mycobacterium paratuberculosis via pasteurised milk: A modelling approach. Vet Rec 1998;143:293-296.

Nielsen SS, Ersbøll AK. Age at occurrence of Mycobacterium avium subspecies paratuberculosis in naturally infected dairy cows. J Dairy Sci 2006;89:4557-4566.

Nielsen SS, Toft N. Ante mortem diagnosis of paratuberculosis: A review of accuracies of ELISA, interferon-gamma assay and faecal culture techniques. Vet Microbiol 2008;129:217-235.

Nielsen SS, Toft N. Temporal development of antibodies to Mycobacterium avium subsp. paratuberculosis infection in cattle. 11th International Colloquium on Paratuberculosis, 2012, P024.

Okura H, Toft N, Nielsen SS. Occurrence of Mycobacterium avium subsp. paratuberculosis in milk at dairy cattle farms: A systematic review and meta-analysis. Vet Microbiol 2012;157:253-263.

Rademaker JL, Vissers MM, Te Giffel MC. Effective heat inactivation of Mycobacterium avium subsp. paratuberculosis in raw milk contaminated with naturally infected feces. Appl Environ Microbiol 2007;73:4185-4190.

Stabel JR, Palmer MV, Harris B, Plattner B, Hostetter J, RobbeAusterman S. Pathogenesis of Mycobacterium avium subsp. paratuberculosis in neonatal calves after oral or intraperitoneal experimental infection. Vet Microbiol 2009;136:306-313.

Stephan R, Schumacher S, Tasara T, Grant IR. Prevalence of Mycobacterium avium subspecies paratuberculosis in Swiss raw milk cheeses collected at the retail level. J Dairy Sci 2007; 90:3590-3595.

Sweeney RW, Uzonna J, Whitlock RH, Habecker PL, Chilton P, Scott P. Tissue predilection sites and effect of dose on $\mathrm{Myco}^{-}$ bacterium avium subs. paratuberculosis organism recovery in a short-term bovine experimental oral infection model. Res VetSci 2006;80:253-259.

Weber MF, Nielen M, Velthuis AG, van Roermund HJ. Milk quality assurance for paratuberculosis: Simulation of withinherd infection dynamics and economics. Vet Res 2008;39:12.

Whitlock RH, Wells SJ, Sweeney RW, Van Tiem J. ELISA and fecal culture for paratuberculosis (Johne's disease): Sensitivity and specificity of each method. Vet Microbiol 2000;77:387-398.

Whittington R. Cultivation of Mycobacterium avium subsp. paratuberculosis. Behr MA, Collins DM (eds.). CAB International, 2010, pp. 244-266.

Wilmink JBM. Adjustment of lactation yield for age at calving in relation to level of production. Livest Prod Sci 1987;16: 321-334.
Address correspondence to: Hisako Okura, DVM 2-3-18 Hazawa Nerimaku Tokyo, 176-0003 Japan

E-mail: pfq476@alumni.ku.dk 